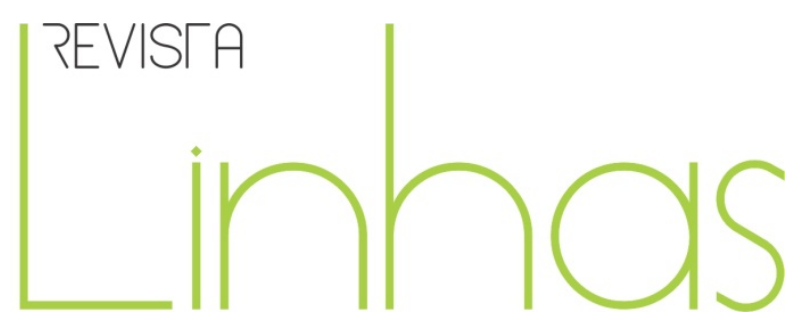

\title{
Injustiças. A experiência das desigualdades no mundo do trabalho - Fraçois Dubet com Valérie Caillet, Régis Cortésério, David Melo, Françoise Rault
}

Injustices. L'expérience des inégalités au travail, Éditions du Seuil . Paris, França: 2006.

\author{
Julia Siqueira da Rocha \\ Doutoranda no Programa de Pós- \\ Graduação em Educação na \\ Universidade Federal de Santa Catarina \\ - PPGE/UFSC. \\ jsiqueiradarocha@gmail.com

\section{Paulo Sérgio da Graça Delgado} \\ Graduando $8^{\text {a }}$ fase do Curso de \\ Pedagogia na Universidade Federal de \\ Santa Catarina - UFSC. \\ paulodelgado_9@hotmail.com \\ Verônica Ivone Formiga \\ Graduando $8^{\text {a }}$ fase do Curso de \\ Pedagogia na Universidade Federal de \\ Santa Catarina - PPGE/UFSC. \\ veronicapedagogia2010@hotmail.com
}

\section{Para citar esta resenha:}

ROCHA, Julia Siqueira da; DELGADO, Paulo Sérgio da Graça; FORMIGA, Verônica Ivone. Injustiças. A experiência das desigualdades no mundo do trabalho - Fraçois Dubet com Valérie Caillet, Régis Cortésério, David Melo, Françoise Rault. Revista Linhas, Florianópolis, v. 14, n. 27 ,jul./dez. 2013. p. 313- 321 
A obra Injustiças. A experiência das desigualdades no mundo do trabalho ${ }^{1}$ tem por objetivo descrever e analisar os estatutos normativos e morais da experiência das desigualdades no trabalho. A intenção dos autores ${ }^{2}$ é mostrar que os sentimentos de (in)justiça dos atores sociais dependem das condições que lhes são dispostas no mundo do trabalho. No entanto, cada ator social possui uma dinâmica própria para construir a sua experiência moral e também a sua experiência social sobre as desigualdades no trabalho.

A análise dessas experiências ocorre por meio de uma pesquisa que se estendeu por quase três anos, tendo sido realizada em três etapas, primeiramente foram feitas 350 entrevistas individuais, 251 delas compuseram o corpus deste estudo; em seguida foram organizados debates com 11 grupos focais de trabalhadores, abrangendo 1.144 trabalhadores: agricultores, auxiliares de enfermagem, professores-pesquisadores precários, caixas de supermercado, intermitentes do espetáculo, motoristas de taxi, chefes de setor, jovens executivos, modistas e costureiras, operários da construção civil e agentes da agência nacional de emprego.

O livro compõe-se de 10 capítulos, além da introdução, conclusão e do anexo metodológico. Nos primeiros capítulos pudemos observar a maneira pela qual os autores põem em prática os três princípios de justiça fundamentais: igualdade, mérito e autonomia. O quarto capítulo discute as formas de articulação desses princípios com os problemas relacionados ao direito, ao poder e ao reconhecimento. O quinto capítulo procura mostrar o modo como o caráter contraditório dos princípios de justiça produz uma crítica sem fim. Os três capítulos seguintes visam analisar os sentimentos de injustiça nas situações sociais em que estes se formam. O nono capítulo aborda a

\footnotetext{
${ }^{1}$ Injustiças. A experiência das desigualdades no trabalho (Injustices. L'expérience des inégalites au travail) originalmente publicada em francês por Éditions du Seuil, em março de 2006, Paris, França.

Será publicada no Brasil em 2014 pela Editora UFSC com tradução de Ione Ribeiro Valle. Esta resenha foi realizada com base nos originais desta tradução.

${ }^{2}$ François Dubet é professor de sociologia na universidade de Bordeux II e diretor de estudos na École des Hautes Études en Science Sociales (EHESS); Valérie Caillet é mestre de conferências de sociologia na Institut Universitaire de Formation des Maîtres (IUFM) de Versailles. Régis Cortéséro é doutor em sociologia; David Mélo é mestre de conferências de sociologia na universidade de Orléans; Françoise Rault é doutor em sociologia, professor de ciências econômicas e sociais em liceu.
} 
distância entre a ação e os julgamentos de justiça. Por fim, o capítulo 10 e a conclusão referem-se à experiência individual face às injustiças, revelando que elas podem ao mesmo tempo destruir e reforçar a subjetividade dos sujeitos.

Quando os autores tratam do princípio de igualdade, ressaltam que ele é ao mesmo tempo o mais evidente e o mais complexo. Assim, afirmam que as desigualdades só são autênticas à medida que são comparadas com as representações das desigualdades consideradas como justas. Dubet e seus parceiros nos mostram que participantes da pesquisa misturam duas concepções acerca da igualdade: a igualdade de posições e a igualdade de oportunidades, de tal modo que este princípio só pode ser aprendido na tensão entre a igualdade fundamental dos sujeitos e as desigualdades sociais reais. Cada um considerara justo e igual aquilo que entender como necessário para manter sua posição na hierarquia social. Ainda, tratando do princípio de igualdade, os autores mostram que ele aparece como uma condição fundamental para o desenvolvimento de outro princípio de justiça, o mérito.

Tratando-se do modo como o sentimento de (in)justiça é concebido no campo do trabalho, os autores demonstram como a justiça distributiva está vinculada ao mérito. Assim, o trabalhador refere-se ao que é justo avaliando e medindo as adequações entre o que contribui e as retribuições que pode tirar dessa relação. O trabalho é visto como uma forma de sacrifício que é trocado por um valor positivo, o dinheiro. Neste sentido, o mérito também possui um valor moral. Para os participantes da pesquisa analisada este princípio permite pôr em prática sua liberdade, pois graças ao trabalho não se deve nada a ninguém. Os autores destacam ainda que o mérito pode ser percebido como uma forma de realização para os trabalhadores ou como uma forma de negação. Para exemplificar, sublinham como os diretores de empresas podem utilizar o mérito como um meio para intensificar as competições produtivas, colocando em risco a igualdade de base, a autonomia e o respeito por si. Desta maneira, se o mérito é um dos princípios de justiça reivindicado ele não deveria alastrar-se por tudo, pois afetaria outros princípios.

Ao apresentar o terceiro princípio, a autonomia, os autores retomam os princípios de igualdade e de mérito e apontam que se no princípio de igualdade os indivíduos mesclam a igualdade de posições e a igualdade de oportunidades, no 
princípio de mérito eles regulam a equidade da retribuição entre elas, a renumeração de seu trabalho. Desta forma, o engajamento do indivíduo no seu trabalho proporciona-lhe satisfações pessoais como: prazer, felicidade e um sentimento de liberdade, mas, também pode provocar o sentimento de ser alienado, destruído e até mesmo tratado como um objeto de uso.

É por esses julgamentos, que pode ser definido o princípio da autonomia, que de forma mais ampla refere-se ao contentamento pessoal e social do postulado metafísico de liberdade. Nesta perspectiva, a autonomia é um princípio de justiça, pois medindo as satisfações e aflições pautadas na atividade do trabalho, o indivíduo mede a equidade de sua sorte. Assim, o que pode Ihes fortalecer no trabalho também pode lhes destruir. $O$ princípio da autonomia não deve ser confundido com o princípio da igualdade ou do mérito, ele é específico, pois todos os indivíduos o mobilizam na medida em que almejam tornar-se sujeitos de seu trabalho.

Nem todos os sentimentos de injustiça derivam diretamente da igualdade, do mérito e da autonomia. O fato de que os empregadores ou os colegas não respeitam as regras do direito do trabalho são vivenciadas como profundas injustiças, da mesma forma, os abusos de poder, a perseguição e as ameaças constituem-se como espaços de críticas intermediárias. Portanto, o espaço do direito e das regras estabiliza e organiza a tensão entre o fato de sermos iguais e o fato de que o trabalho nos organiza e nos hierarquiza em função do nosso mérito individual.

Como o direito do trabalho, o poder é ambivalente e ambíguo porque é simultaneamente uma opressão e um recurso. O poder circula e, na organização, ele circula entre dois polos: de um lado, a capacidade dos dirigentes de impor suas escolhas em nome da racionalidade e dos imperativos econômicos; de outro, a capacidade de cada trabalhador construir seu espaço de autonomia a fim de que o trabalho se realize. Quando o desequilíbrio entre esses dois polos é absoluto, os indivíduos denunciam a tirania dos chefes, sobretudo quando o poder destes extravasa a esfera da organização do trabalho. O poder é também criticado quando é muito fraco, quando não consegue acalmar o jogo das invejas, quando ameaça a sobrevivência das empresas e das organizações. 
O reconhecimento não é um ser, mas um processo, ele aparece primeiramente de forma negativa, menos como um sentimento de plenitude que como uma negação. $O$ aspecto negativo ou profundo do reconhecimento acontece quando ele se forma na articulação entre dois princípios de justiça. De um lado, queremos ser reconhecidos porque somos iguais a todos os outros, e a falta de reconhecimento deriva portanto do desprezo e da desigualdade. Por outro, esta igualdade supõe um risco de negação da autonomia singular que cada um reivindica. Assim, o pedido de reconhecimento é sempre ambivalente e parece duplamente ameaçado, seja porque a singularidade nos fecha, seja porque a igualdade nos nega como indivíduo singular.

Após criticarem suas condições de trabalho em nome da igualdade, do mérito e da autonomia, o que se pode considerar como críticas internas a cada princípio, os entrevistados desenvolvem críticas externas opondo os princípios entre si. Ao se colocarem do ponto de vista da igualdade, os trabalhadores pensam que o mérito, aprofunda as desigualdades, apontando a autonomia individual que fragmenta a comunidade moral e a solidariedade. Esses mesmos trabalhadores frente ao mérito, percebem a igualdade como uma ordem hierárquica imutável feita de privilégios que bloqueiam o livre jogo do mérito, enquanto a autonomia é percebida como um fator de desordem e de favoritismo. Ao analisar o princípio da autonomia, a crítica se volta à igualdade assinalando que o igualitarismo destrói a responsabilidade. O mérito por sua vez apresenta-se como um princípio cruel que destrói a identidade e a autonomia ética de cada um.

A fixação atual do discurso contestatório na lógica neoliberal aparece como um sintoma: não é a um ator dominante que são imputados os males sociais, mas a um sistema anônimo e impessoal. Não é ao capitalismo e a seus promotores que os entrevistados atribuem as injustiças, mas aos pequenos chefes "sádicos", aos empregadores sem escrúpulos ou ainda a seus colegas. E quando o sentimento de injustiça é atribuído à própria sociedade, aplica-se a dimensões que escapam à imagem do conflito de classes, como o racismo, as desigualdades entre os sexos e as gerações, a precariedade, entre outros. Os trabalhadores não conseguem, nessas condições, inscrever seus sofrimentos numa representação conflituosa organizada da vida social na 
qual os dominantes seriam culpados pelas injustiças a que os submetem. Consequentemente é mais em termos morais que em termos políticos que os atores interpretam suas experiências.

De maneira geral, a noção de organização do trabalho designa a sua divisão técnica, quer dizer, as modalidades da repartição das tarefas visando à eficiência produtiva. Ela remete, por um lado, a uma divisão vertical das tarefas abrangendo a distribuição das posições hierárquicas no centro da empresa. Por outro, observa-se uma divisão horizontal das tarefas que organiza a repartição de uma operação ou de um serviço em funções de trabalhos diferenciados. No entanto, do ponto de vista sociológico, a organização do trabalho não se reduz a um funcionamento técnico, na medida em que exprime uma vontade gerencial de controle do trabalho, ela se constitui em jogo de poder e de conflitos. A organização não se resume, portanto, a um agenciamento funcional de tarefas e funções visando eficiência técnica, mas também distribui posições, atribui lugares aos trabalhadores e constrói desigualdades.

Por trás de cada tipo de organização do trabalho existem princípios de justiça que fundam a desigualdade das posições e dos recursos. Distinguem-se três tipos "puros" de organização, a racionalização taylorista, a individualização e a burocracia profissional. Cada um deles se apoia sobre um princípio pivô: igualdade, mérito ou autonomia, associados a um segundo princípio de justiça, ainda que critique ou combata um ao outro. A racionalização taylorista apoia-se fundamentalmente no mérito, e menos na igualdade, contra a autonomia. A individualização é sustentada por uma crítica da igualdade em nome do mérito, e secundariamente da autonomia. Enfim, as burocracias profissionais amparam-se na igualdade, contra o mérito, garantindo a autonomia.

Cada meio profissional tem sua própria configuração dos princípios de justiça. Em todos os universos de trabalho, os desajustamentos entre os princípios de justiça e as situações concretas de trabalho provocam um discurso crítico acirrado no qual a demanda por justiça transforma-se com frequência em demanda por justeza. Nesse sentido, o discurso crítico talvez seja menos uma denúncia do que uma tentativa obstinada de construir um equilíbrio e de assentar uma identidade. 
A ligação entre os sentimentos de injustiça e a ação talvez não seja tão direta quanto se tenha pensado a priori. Não basta estar revoltado com as injustiças para agir; de mais a mais, os que se mobilizam não parecem ser necessariamente mais sensíveis às injustiças que os outros. É importante lembrar que se os princípios de justiça fundam a crítica das injustiças, eles também definem as desigualdades consideradas como justas. Quando se coloca do ponto de vista do mérito e da autonomia, não é certo que todas as situações que poderiam parecer justas o sejam verdadeiramente. Os indivíduos se interrogam para saber se as vítimas das injustiças são realmente vítimas, se as injustiças acontecem por acaso e se o azar não escolhe os que o merecem? Observa-se que o desemprego e a precariedade aparecem como as desigualdades mais escandalosas, e que a maioria das pessoas recusa o racismo e, nas entrevistas individuais, muitas falam das "periferias" como bairros onde se cristalizam todas as injustiças sociais, todas as misérias do mundo. Entretanto, a denúncia das injustiças não supõe que as vítimas sejam percebidas como inocentes e simpáticas. Para agir é preciso pensar que as vítimas são verdadeiramente inocentes, mas é preciso também estar consciente de que nem sempre se é culpado ou parcialmente cúmplice das injustiças que se denuncia. A suspeita de culpabilidade volta-se contra si mesmo e, quando os indivíduos duvidam, parece preferirem produzir justiça num ambiente imediato, em torno de si, do que mudar o mundo. Uma das consequências dos sentimentos difusos de culpabilidade e de comprometimento é que os atores estabelecem arranjos locais, procurando colocar em prática espaços de justiça limitados. Denunciar injustiças é sempre trair um pouco a lei de seu meio. Quer se tratem de interesse ou de sentimentos de injustiça, os fatores que freiam ou favorecem a passagem à ação podem ser de mesma natureza.

Assim, a relação com o mundo passa por uma relação consigo mesmo. Ainda que as injustiças sejam definidas por categorias normativas, elas são também experiências subjetivas, sentimentos e emoções que participam da formação, às vezes da destruição, dos sujeitos, pelo abatimento, pela cólera, pelo desligamento. Da mesma maneira que "os ferimentos da alma" parecem decorrer de uma falta de reconhecimento, a resignação e o medo parecem remeter mais diretamente aos excessos de poder e à tirania. 
O lugar do trabalho na sociedade e na vida dos indivíduos não está perto de se reduzir como se pensou outrora. E o fato de gostar de seu trabalho não elimina a crítica das injustiças. Somos simultaneamente cada vez mais individualistas e cada vez mais iguais. Enquanto se imaginara sociedades sem classes, atualmente temos classes sem sociedade.

Cada universo de trabalho possui sua própria gramática dos sentimentos de injustiça sem que se possa correlacioná-la imediatamente a uma posição na estrutura social. O fato de se situar entre os mestres do mundo, mais ou menos abstratos, e os estrangeiros e os excluídos, frequentemente mais próximos, pesa muito sobre o sentimento de injustiça. Os sentimentos de (in)justiça desenvolvem-se em três espaços sociais relativamente distintos: o das condições de trabalho; o das clivagens devido às condições de acesso ao emprego; o de uma sociedade limitada, de um lado, por uma superelite pouco visível e todo poderosa e, de outro, pelos excluídos percebidos simultaneamente como vítimas e como uma ameaça.

Numa perspectiva ideal, a igualdade, o mérito e a autonomia formam um conjunto de princípios fortemente integrados e unidos por ligações necessárias: nossa igualdade decorre de sermos igualmente livres e nosso mérito só é justo na medida em que somos livres e iguais. Ainda que sejamos todos iguais em direitos, parece claro que não o somos totalmente e que uma grande loteria teria distribuído desigualmente a força, a beleza, a inteligência, o talento, a coragem, a virtude. E quanto mais se pensa que a igualdade é a igualdade de oportunidades, mais se confronta com esta evidência sobre a qual parece impossível agir.

No trabalho, o mundo justo só pode ser pensado em termos de ajustes locais entre princípios contraditórios. A sociedade justa não é a sociedade perfeita, não é a sociedade virtuosa, mas a que possibilita aos indivíduos serem sujeitos que combinam os princípios de justiça, permitindo-lhes viverem a vida que consideram como boa para si. Os indivíduos tentam ser justos numa sociedade que não o é e que, talvez, não possa sêlo. Sem jamais renunciar à cólera e à luta, é também na busca do bem que cada um resiste à tirania e aos impasses do justo. 
Como o leitor pode perceber, esta obra sociológica traz importantes contribuições não apenas para o seu campo, mas às distintas áreas do conhecimento que podem, pelas conclusões por ela reveladas, ampliar os saberes das relações humanas no mundo do trabalho.

Recebido em: 01/04/2013 Aprovado em: 01/07/2013

Universidade do Estado de Santa Catarina - UDESC Programa de Pós-Graduação em Educação - PPGE Revista Linhas Volume 14 - Número 27 - Ano 2013 revistalinhas@gmail.com 